\title{
CONSIDERAÇÕES SOBRE DIREITO, LIBERDADE E ESTADO EM KANT, TOCQUEVILLE E STUART MILL
}

\author{
Área temática: Ciências Humanas/História \\ Germano Moreira Campos ${ }^{1}$ \\ ${ }^{1}$ Mestre em História pela UFOP e professor no curso de História na Faculdade de Ciências \\ Gerenciais de Manhuaçu (FACIG).
}

\begin{abstract}
RESUMO
O presente artigo se dedica a desenvolver uma síntese do pensamento político-filosófico de Immanuel Kant, e, ainda, fazer uma certa aproximação com os ideais de Aléxis de Tocqueville e John Stuart-Mill, de acordo com assuntos específicos. Kant, filósofo alemão do século XVIII, desenvolveu seu pensamento baseado, fundamentalmente, na razão e na concepção de liberdade que ela lega ao homem. A natureza tem importante função na elevação do indivíduo; e - Estado, na visão kantiana, exerce e sofre ação dos homens entendidos enquanto sociedade. As noções de liberdade, Estado, direito e mesmo a idéia de cidadão (indivíduo) têm semelhanças e distanciamentos que se tornam evidentes quando comparados aos pensamentos desses três legítimos "analistas" das situações e das instituições de seu tempo. Houve uma certa dificuldade para chegar a tais considerações, pois a contradição é marca presente - internamente - nesses pensadores, embora Tocqueville chegue a ser, dentre todos, o mais claro nas suas definições, embora seja bastante pessimista quanto à sua análise.
\end{abstract}

Palavras-chaves: Direito; Estado; Indivíduo.

\section{ABSTRACT}

This article is dedicated to developing a synthesis of political and philosophical thought of Immanuel Kant, and also to a certain approximation to the ideals of Alexis de Tocqueville and John Stuart Mill, in accordance with specific issues. Kant, German philosopher of the eighteenth century, developed his thinking based fundamentally on reason and conception of freedom that she bequeaths to man. Nature plays an important role in the elevation of the individual, and the state, in the Kantian view, exercises and action of men suffer understood as a society. The notions of freedom, rule, law, and even the idea of citizen (individual) have similarities and differences that become evident when compared to the thoughts of these three legitimate "analysts" of situations and institutions of his time. There was some difficulty in arriving at such considerations as the contradiction is this brand - internally - these thinkers, though Tocqueville comes to be, of all the more clear in its definitions, although it is quite pessimistic about their analysis.

Keywords: Law, State, Guy. 


\section{A FILOSOFIA RACIONAL E POLÍTICA DE KANT}

Immanuel Kant ganhou destaque, principalmente, através do texto-panfleto Resposta à Pergunta: Que é "Esclarecimento"?; em que lançou explicações a respeito do que viria a ser o termo esclarecimento ou lluminismo (Aufklarung) na sua visão. Kant destaca muito o "uso público da razão" como sendo o grande responsável para que o homem abandone a situação de menoridade e atinja grau de maioridade (KANT, 1974, p. 100).

O estado de menoridade é tido como injusto, e a natureza - a oposição por ela gerada - faz com que o desenvolvimento do homem se torne uma necessidade; um "imperativo categórico". O indivíduo agiria sempre visando a um fim - "teleologia" - para atingir os objetivos por ele almejados. Para Kant é possível que todos os cidadãos se esclareçam usando a razão (através de publicações que possam atingir as massas a ponto de norteá-las), especialmente em conjunto; mas ele também diz que esse processo é difícil e lento, o que explica a pouca quantidade de homens esclarecidos existentes no mundo de sua época.

Voltando à razão, esta pode chegar a atuar como uma espécie de "Deus" em Kant; ela guia os indivíduos rumo a um futuro que tende a ser bom, se este homem for esclarecido - se ele não precisar de um tutor que o norteie, como ocorre na menoridade. Acontece o que se chama de "democratização do debate", e a ética tende a aumentar juntamente com a aplicação da razão.

No tocante à política, Kant lança previsões e fala da necessidade de uma "Constituição civil que administre Universalmente o direito" (KANT, 1986); deixando os países numa situação de igualdade de condições. Isto seria quase que uma determinação, e quando esta condição fosse atingida, a natureza diminuiria seu ferrenho jogo de oposições lançadas sobre os homens, as guerras diminuiriam - pois, segundo Kant, acabar por completo não seria bom, porque deixaria o homem acomodado -,e o mundo se aproximaria daquilo que Kant chamava de "paz perpétua", um empecilho ao pleno desenvolvimento dos homens e dos Estados.

O caráter absolutista de Kant é mostrado quando prega a necessidade imprescindível do Estado para controlar as liberdades, e possibilitando-as a um "número mais amplo de pessoas". Os conceitos de liberdade e segurança meio que se misturam nesse filósofo, diferente daquilo que observa em pensadores como Hobbes - que defende a troca da liberdade do estado de natureza pela segurança do Estado civil - e Rousseau - defensor do "bom selvagem".

\section{A NOÇÃO DE LIBERDADE E SUAS CONSIDERAÇÕES: INDIVÍDUO E SOCIEDADE}

A noção de liberdade é uma das mais importantes e também das mais contraditórias quando se analisa os três pensadores que são alvo deste trabalho. Para Kant, este é o bem mais importante que o homem pode ter.

Através da liberdade kantiana, cada cidadão deve atuar como um legislador dentro da sociedade - Estado pensamento compartilhado com Tocqueville. "Ninguém me obriga a ser da maneira dos outros" (KANT, 1974, p. 56), esta frase representa bem a visão de Kant. Nele, a questão da liberdade vem a ser tão forte que chega a afirmar que nem mesmo o Estado pode evitar que o homem atue livremente. Mas as controvérsias em Kant se dão mais fortemente também no tocante à

\footnotetext{
${ }^{1}$ Para maiores informações, conferir as obras de Hobbes e Rousseau, com destaque para $O$ Leviatã, do primeiro, e O Contrato Social, deste.
} 
liberdade. Até que ponto a determinação da natureza nos dá liberdade? Dá para se ir além do imperativo categórico e da eleologia? São questões que se levantam.

Já Stuart-Mill chega a ser tão categórico nessa questão da liberdade, que chega mesmo a enumerar as condições para que ela exista: "1) de quantas portas estão abertas ao público; 2) da facilidade ou dificuldade de se atingir os objetivos; 3) de até que ponto elas são abertas ou fechadas por atos humanos deliberados" (BERLIM, 1979, p. 162). Enquanto Kant vê a liberdade mais no plano individual, Mill e Tocqueville pensam esta questão relacionada à igualdade entre as pessoas.

A liberdade em Kant, em geral é vista com bons olhos, ao passo que Mill fala da existência de duas noções de liberdade: uma positiva (quando o indivíduo se torna um gestor de si mesmo) e outra negativa (excessiva, onde um cidadão acaba limitando o outro). Para Mill só era considerada humana aquela sociedade onde a liberdade fosse totalmente respeitada. Tocqueville, algumas vezes, chega a afirmar que a liberdade individual excessiva é ruim para uma nação; e ele toma como base a situação da Europa, haja vista a falta de mobilização popular como sendo trágica para os países. Ainda em Tocqueville, a liberdade era reconhecida como sendo a ausência de arbitrariedade; onde esta seria o motor de muitas revoluções, o que este autor se põe contra, por considerar que elas só fazem aumentar a opressão do Estado.

Kant fala que a razão - que vai gerar a liberdade - é comum a todo ser humano; e Stuart-Mill infere que é a liberdade o diferencial entre homens e animais. Mas apenas em Kant a situação de liberdade é tida como totalmente positiva, pois Tocqueville e Mill consideram que chega um ponto em que ela desagrega a

sociedade - através do individualismo excessivo -, prejudicando a mobilização do povo. Enquanto a liberdade kantiana é mais individual, Tocqueville privilegia ao todo; o grupo.

Como foi referido, o termo liberdade individual em Kant, vale considerar a concepção que ele tinha de cidadão, onde se pode evidenciar uma face do conservadorismo kantiano: só era considerado realmente como cidadão aquele que tivesse "liberdade, igualdade e independência" (BOBBIO, 2000, p. 137).

Os dois primeiros são comuns à maioria das pessoas, mas este último diz respeito a bens, recursos, possessões - o que excluía a maioria dos ditos "cidadãos": poucos, para Kant eram reconhecidos como reais cidadãos. $E$ isto representa uma oposição com Tocqueville, que tem na igualdade entre as pessoas a base de sua análise; Ele fala da existência de cidadãos ativos (que promovem ações no meio) e passivos (que são influenciados pelos outros).

Tocqueville apresenta também os diferentes tipos de ação social²:

1- Ação social racional com respeito a fins: uma ação puramente racional, "de mercado";

2- Ação social racional com respeito a valores: presença da moral;

3- Ação social tradicional

4- Ação social afetiva.

\section{AS CONSIDERAÇÕES SOBRE O ESTADO}

$\mathrm{Na}$ filosofia kantiana, o que também pode ser encontrado nos outros dois pensadores, o Estado é tido como essencial para manter, através de suas instituições, a liberdade e os direitos de um povo. $O$ que vai os diferenciar serão as formas de como este Estado é visto.

A visão de Kant - guardadas as devidas proporções - assemelha-se à de Hobbes, onde o Estado limita a liberdade ampla que se tinha no estado de natureza para manter a ordem; e alguma liberdade ainda é garantida ao povo. Uma ordem artificial é imposta, onde o governo atua,

\footnotetext{
${ }^{2}$ Algo muito semelhante também poderáser observado em Max Weber algum tempo depois. Conferir em WEBER, Max. Economia e sociedade: fundamentos da sociologia compreensiva. Brasília: Ed. da UnB, 1999 (vol. 2).
} 
por meio de leis, para se impor. É um dever jurídico do Estado, possibilitar aos cidadãos a felicidade. A forma de governo preferida de Kant é o sistema republicano, onde o poder legislativo é muito atuante.

O governador do povo - o rei - não é perfeito, pois também é um homem e, logo, pode cair no erro. Mill já definiria que "há poderes que são muito pesados para a mão humana" (BERLIM, 1979, p. 157). É interessante notar que Tocqueville, Kant e nem mesmo Mill têm a revolução como sendo a melhor solução contra um poder que está se mostrando maléfico para seu povo.

Um ponto onde as considerações dos três seguem o mesmo caminho é no tocante à visão que têm de um Estado paternalista; visto como sendo um mal, pois limita, ou mesmo impede, que seus cidadãos cresçam. Seria uma situação de covardia a ser imposta à população. Tocqueville discorre principalmente sobre a situação dos países da Europa (caótica) frente ao caso especial dos Estados Unidos (TOCQUEVILLE, 1969, p. 135). Há um temor quanto à situação da primeira e um engrandecimento deste último - através da forma pela qual o Estado foi montado a partir dos seus cidadãos. Tocqueville tem a justiça como sendo a melhor forma de se analisar a situação de um país. A queda de muitos governos, a seu ver, estaria no fato de que os governantes se tornariam injustos de exercer o poder que têm em mãos. A democracia é a forma preferida de Tocqueville para um governo; o que difere, como já vimos, de Kant, que, embora queira uma república, não almeja a democracia.

Kant é menos realista quanto à situação em que as coisas se encontram do que Mill e Tocqueville. Neste, "A igualdade constitui a lei social" (ARON, 1985, p. 56). É muito importante ao estudo da sociedade para se compreender as questões políticas. É exaltada a necessidade de todos os países implantarem uma Constituição Federativa: "O maior mérito das leis americanas" (TOCQUEVILLE, 1969, p. 122). É meio que uma aproximação à idéia de "Constituição Civil que Administre Universalmente o Direito", sugerida por Kant. Mas enquanto este valoriza a existência e a aplicação das leis, Tocqueville exalta o perigo que um fortalecimento do legislativo pode acarretar: a morte das democracias. A importância que Kant dava à razão é aplicada, por Tocqueville, ao ideal religioso, para que os costumes sejam definidos - coisa muito importante em sua análise. $O$ espírito de religião vem unido ao espírito de liberdade.

A consolidação de um Estado marca, fundamentalmente, a saída do estado de natureza; mas Tocqueville se mostra bastante preocupado com a situação em que a Europa estaria se encontrando - principalmente a França. Ele chega a falar sobre certa regressão desses países ao primitivo estado de natureza que a individualidade excessiva veio a causar - visão pessimista. Para Tocqueville, a liberdade existente hoje progresso espiritual e principalmente material - é menor que a de tempos anteriores. A ambição e a necessidade das pessoas de ter algo levou a essa situação crítica de competição individual na Europa, enquanto outras sociedades a norte-americana - estariam se desenvolvendo através da cooperação (mobilização).

\section{A ÉTICA E SUAS APLICAÇÕES}

Stuart-Mill compartilha com Kant a idéia de que o indivíduo não evolui no tempo; o que realmente se amplia é a cultura, a erudição. É da razão a grande responsabilidade de fazer com que o homem evolua até o seu limite. É interessante, ainda, que Kant chegou a afirmar que se deve crer em algo, para isso ele próprio considerou que teve de limitar sua razão, para que fosse aberto espaço para considerações religiosas.

Como tudo em Kant, sua ética é totalmente impregnada pelo espírito da razão. De acordo com ele, o "bem da humanidade" norteia a escolha do que é "bom", em detrimento do que seria tido como sendo "mau" para o futuro da humanidade. Logo, se o indivíduo exerce 
uma ação, é porque é legítimo que ele a faça.

A ética aumentaria e iria se consolidar de vez quando fosse atingida uma situação em que os indivíduos se respeitassem mutuamente. Para isso, seria necessário que o estado de natureza (injusto) fosse abandonado e a Constituição civil se instalasse. A base desse sistema - que visa valores universais - é que cada indivíduo respeite as liberdades do outro; o que gera a idéia de que "é legítimo o que é justo" (pensamento utilitarista). Mill (2001) se relaciona a esta concepção quando afirma que "justo é o que é útil"; onde a liberdade "negativa" pode ser vista como antiética.

O Estado é visto como um corpo, além de coletivo, moral. Segundo Mill, esta ação moral do Estado se justificaria pela autoproteção que ele deve fazer para evitar qualquer agressão ou dano que algo fosse lhe causar, e, conseqüentemente, à sua população. Tocqueville exalta a importância da ética religiosa na formação dos Estados Unidos.

Kant e Mill não consideram a existência de uma verdade absoluta; e aquilo que for descartado como sendo uma mentira, poderá levar consigo uma parcela de verdade. A coisa mais antiética que poderia existir seria um governo autoritário, segundo Mill e Tocqueville.

\section{CONCLUSÃO}

Através do que foi apresentado, pode-se observar o posicionamento desses três grandes homens, no campo dos conceitos políticos e no tocante aos direitos - em termos gerais - do povo. Como foi dito na introdução deste trabalho, não é fácil descrever a filosofia dos autores considerados; pois eles apresentam, como no caso de Kant, contradições internas e, principalmente, quando se toma um em relação ao outro.

Ao mesmo tempo em que aparentam ser facilmente compreensíveis, lançam na mente de seus leitores as mais complicadas teorias político-sociais. Espero ter relacionado corretamente o pensamento desses excelentes autores, o que foi o objetivo maior deste trabalho.

\section{REFERÊNCIAS BIBLIOGRÁFICAS}

ARON, Raimmond. Estudos políticos. Brasília: Editora da Universidade de Brasília 1985.

BERLIN, Isaiah. Quatro ensaios sobre a liberdade. Brasília: Editora da Universidade de Brasília, 1979.

BOBBIO, Norberto. Direito e Estado no pensamento de Emmanuel Kant. São Paulo: Mandarim, 2000.

HOBBES, Thomas. Leviatã São Paulo. Abril Cultural, 1988.

KANT, Emmanuel. Resposta à pergunta: Que é "Esclarecimento"? In: Textos Seletos. Petrópolis: Editora Vozes, 1974.

KANT, Emmanuel. Idéia de uma história universal de um ponto de vista cosmopolita. São Paulo: Editora Brasiliense, 1986.

ROUSSEAU, J. J. O Contrato social. São Paulo: Martin Claret, 2001.

STUART-MILL, J. Sobre a liberdade. Petrópolis: Vozes, 1991.

TOCQUEVILLE, Aléxis de. Democracia na América. São Paulo: Editora Nacional, 1969.

WEBER, Max. Economia e sociedade: fundamentos da sociologia compreensiva. Brasilia: Ed. daUnB, 1999 (vol. 2). 